\title{
PENGARUH STRES KERJA, KOMPENSASI DAN TINGKAT KEPUASAN KERJA TERHADAP TURNOVER INTENTION KARYAWAN PT. WAHANA JAYA KIRANA DI JAKARTA
}

\author{
Mochammad Mabror \\ STIE Unisadhuguna Jakarta, Indonesia \\ Email : mohamad.mabror@ubs-usg.ac.id
}

\begin{abstract}
Abstrak
Pendahuluan : Sumber daya manusia merupakan satu-satunya sumber daya yang memliki akal perasaan, keinginan, keterampilan, pengetahuan, dorongan, dan karya. Bertambahnya beban kerja dan faktor-faktor lain dapat menimbulkan stres dan ketidaknyamanan bagi karyawan sehingga mengganggu kinerjanya, jika hal tersebut terjadi secara terus-menerus maka keinginan untuk berpindahpun semakin kuat.

Tujuan : Tujuan dari penelitian ini adalah untuk menentukan apakah ada korelasi antara efek stres kerja, kompensasi, dan tingkat kepuasan kerja pada niat pergantian karyawan PT. Wahana Jaya Kirana di Jakarta.

Metode : Penelitian ini dilakukan pada Januari 2020 menggunakan google form (kuesioner online). Data yang digunakan dalam penelitian ini adalah data primer. Populasi dalam penelitian ini adalah seluruh karyawan PT Wahana Jaya Kirana. Sampel yang digunakan dalam penelitian ini adalah 60 responden. Metode pengujian instrumen yang digunakan adalah pengujian validitas dan keandalan. Teknik analisis data yang digunakan adalah analisis regresi linier berganda dan uji $\mathrm{T}$.

Hasil : Hasil penelitian menunjukkan bahwa stres kerja, kompensasi, dan tingkat kepuasan kerja memiliki efek positif dan signifikan pada niat pergantian karyawan.

Kesimpulan : pengujian variabel Stres Kerja secara parsial berpengaruh terhadap Turnover Intention Karyawan di PT. Wahana Jaya Kirana. Hasil pengujian variabel Kompensasi secara parsial berpengaruh terhadap Turnover Intention Karyawan di PT. Wahana Jaya Kirana.
\end{abstract}

\section{Abstract}

Introduction : Human resources are the only resources that have sense of feeling, desire, skill, knowledge, drive, and work. Increased workload and other factors can cause stress and discomfort for employees so that it interferes with their performance, if it happens continuously then the desire to move is even stronger.

Objective : The purpose of this study was to determine whether there was a correlation between the effects of work stress, compensation, and the level of job satisfaction on employee turnover intentions. Wahana Jaya Kirana in Jakarta.

Method : This study was conducted in January 2020 using google form (online questionnaire). The data used in this study is primary data. The population in this study is all employees of PT Wahana Jaya Kirana. The sample used in the study was 60 respondents. The instrument testing method used is a test of validity and reliability. The data analysis techniques used are multiple linear regression analysis and T test.

Results : The results showed that work stress, compensation, and levels of job satisfaction had a positive and significant effect on employee turnover intentions. 
Pengaruh Stres Kerja, Kompensasi dan Tingkat Kepuasan Kerja terhadap Turnover Intention PT. Wahana Jaya Kirana di Jakarta

Conclusion: Testing of work stress variables partially affects employee turnover intentions at PT. Wahana Jaya Kirana. The results of the Compensation variable test partially affect employee turnover intentions at PT. Wahana Jaya Kirana.

Keywords: Turnover Intention, Job Stress, Compensation

\section{Pendahuluan}

Sumber daya manusia merupakan satu-satunya sumber daya yang memliki akal perasaan, keinginan, keterampilan, pengetahuan, dorongan, dan karya. Semua potensi SDM tersebut berpengaruh terhadap upaya organisasi dalam mencapai tujuan (Farchan, 2016).

Bertambahnya beban kerja dan faktor-faktor lain dapat menimbulkan stres dan ketidaknyamanan bagi karyawan sehingga mengganggu kinerjanya, jika hal tersebut terjadi secara terus-menerus maka keinginan untuk berpindahpun semakin kuat (Asih, Widhiastuti, \& Dewi, 2018) . Meskipun turnover intention pada umumnya berdampak buruk terhadap organisasi, turnover intention seringkali dibutuhkan oleh perusahaan yang memiliki karyawan dengan kinerja rendah (Kharismawati \& Dewi, 2016). Cara tersebut dilakukan untuk mengganti karyawan yang memiliki kinerja rendah atau untuk mencari beberapa ahli dibidangnya sehingga dapat meningkatkan produktivitas dan kinerja perusahaan tersebut (Sabilla \& Sri Padmantyo, 2017).

Hal ini tentunya mengakibatkan kecemasan yang kedepannya bisa berakibat tingginya tingkat stres pada karyawan (Dewi \& Sriathi, 2019). Selain itu, dari sisi kompensasi yang diberikan, banyak karyawan yang mengeluhkan kompensasi yang tidak memuaskan terhadap hasil kerja baik finansial maupun non finansial (Khaidir, Bachri, \& Sugiati, 2017).

Menurut (Pangarso \& Ramadhyanti, 2015) ketidakpuasan karyawan terhadap perusahaan baik mengenai kerjasama dengan rekan kerja yang kurang baik dan kondisi kerja yang tidak mendukung. Ditambah juga, tidak adanya kejelasan dalam kebijakan struktur gaji yang dikaitkan dengan prestasi kerja.

\section{Metode Penelitian}

Metode yang digunakan di dalam penelitian ini adalah metode deskriptif kuantitatif (Sugiyono, 2017b). Metode kuantitatif adalah ilmu yang berkaitan dengan tata cara (metode) pengumpulan data, analisa data, dan interpretasi hasil analisis untuk mendapatkan informasi guna penarikan kesimpulan dan pengambilan keputusan. Penelitian ini akan melakukan survey dengan menggunakan alat kuisioner sebagai instrumen pengumpulan data dan hasil itulah akan diolah dengan software SPSS versi 26.

Teknik pengambilan sampel menggunakan teknik Simple Random Sampling, yaitu teknik pengambilan sampel dari anggota populasi yang dilakukan secara acak tanpa memperhatikan strata yang ada dalam populasi itu (Meng, 2013). Pengambilan sampel di dasarkan pertimbangan dari responden di tiga bagian divisi yang difokuskan yaitu 
divisi yang tingkatan Turnover Intention cukup tinggi divisi marketing, merchandising gudang dan operasional gudang.

Berdasarkan kuesioner yang telah disebar oleh penulis terdapat 60 responden yang menjawab untuk dijadikan bahan penelitian dengan pertimbangan bahwa jumlah sampel cukup representative untuk mewakili populasi.

Dalam penelitian ini terdapat dua metode dalam teknik pengumpulan data, yaitu melalui pengumpulan data primer dan data sekunder (Lestari, 2015). Data Primer adalah data yang diperoleh secara langsung dari nara sumber yaitu karyawan di PT. Wahana Jaya Kirana. Dalam penelitian ini, penulis dapat memperoleh data-data yang dibutuhkan dengan menggunakan teknik pengumpulan data kuesioner yang diperoleh dari hasil kuisioner yang disebarkan kepada sampel yang telah ditentukan sebelumnya Setelah data-data yang diperlukan didapat, langkah selanjutnya adalah dengan melakukan uji instrumen. Dalam langkah ini dilakukan dalam 2 (dua) tahap pengujian, yaitu uji validitas dan uji reliabilitas. Untuk menguji validitas kuesioner digunakan rumus korelasi Product Moment Pearson. Sedangkan uji reliabilitas menggunakan alat ukur dengan rumus Alpha Cronbach (Sugiyono, 2016). Dengan Interpretasi koefisien Korelasi r sebagai berikut (Sugiyono, 2017a).

Uji asumsi klasik dalam penelitian ini di lakukan dalam 3 (tiga) pengujian, yaitu: normality test, multicoliinierity test, dan heteroscedasticity test (Arikunto, 2016). Normality test menggunakan metode Kolmogorov smirnov. Multicoliinierity test dilakukan dengan cara menghitung nilai Variance Inflation Factor (VIF) terhadap semua variabel bebasnya. Terjadi multikolinearitas jika nilai VIF > 10,00. Jika nilai VIF $<$ 10,00 korelasi antar variabel bebasnya masih dapat ditolerir (Sugiyono, 2017a). Sedangkan uji heteroskedastisitas menggunakan metode Glejser.

Pengujian berikutnya adalah pengujian parameter, meliputi uji parameter individual (uji statistik t) bertujuan untuk mengukur seberapa jauh pengaruh satu variabel independen secara individual dalam menerangkan variasi variabel dependen dan uji parameter secara simultan. Dan yang terakhir adalah pengujian best of fit model (Susanto \& Agus Ulinuha, 2017).

\section{Hasil dan Pembahasan}

Penelitian yang menggunakan kuesioner/angket, terlebih dahulu harus dilakukan uji instrumen, yang terdiri dari:

\section{a. Uji Validitas}

Hasil uji validitas variabel Stress kerja dapat dilihat pada Tabel 2 berikut.

Tabel 2

Hasil Uji Validitas Variabel Stress Kerja $\left(\mathbf{X}_{1}\right)$

\begin{tabular}{llll}
\hline No & Hitung & Tabel & Keterangan \\
\hline 1 & 0,452 & 0,254 & Valid \\
2 & 0,872 & 0,254 & Valid \\
3 & 0,480 & 0,254 & Valid \\
4 & 0,872 & 0,254 & Valid \\
\hline \multicolumn{4}{c}{ Sumber: Data diolah }
\end{tabular}


Dari Tabel 2 di atas dapat dilihat bahwa untuk masing-masing pernyataan pada variabel stress kerja $\left(\mathrm{X}_{1}\right)$ seluruh instrument dapat dikatakan valid, karena nilai rhitung yang dihasilkan lebih besar dari pada nilai rtabel yaitu 0.254 .

Untuk hasil uji validitas variabel Kompensasi dapat dilihat pada Tabel 3 berikut.

Tabel 3

Hasil Uji Validitas Variabel Kompensasi $\left(\mathbf{X}_{2}\right)$

\begin{tabular}{llll}
\hline No & Hitung & Tabel & Keterangan \\
\hline 1 & 0,466 & 0,254 & Valid \\
2 & 0,812 & 0,254 & Valid \\
3 & 0,789 & 0,254 & Valid \\
4 & 0,605 & 0,254 & Valid \\
\hline \multicolumn{4}{c}{ Sumber: Data diolah }
\end{tabular}

Berdasarkan Tabel 3 di atas, dapat dilihat bahwa untuk masing-masing pernyataan pada variabel kompensasi $\left(\mathrm{X}_{2}\right)$ seluruh instrument dapat dikatakan valid, karena nilai rhitung yang dihasilkan lebih besar dari pada nilai rtabel yaitu 0.254.

Hasil uji validitas variabel tingkat kepuasan kerja $\left(\mathrm{X}_{3}\right)$ dari sampel berjumlah 60 (enam puluh) dengan jumlah pernyataan sebanyak 4 (empat) dapat dilihat pada Tabel 4 berikut.

Tabel 4

Hasil Uji Validitas Variabel Tingkat Kepuasan Kerja (X3)

\begin{tabular}{llll}
\hline No & Hitung & Tabel & Keterangan \\
\hline 1 & 0,778 & 0,254 & Valid \\
2 & 0,703 & 0,254 & Valid \\
3 & 0,553 & 0,254 & Valid \\
4 & 0,627 & 0,254 & Valid \\
\hline
\end{tabular}

Sumber: Data diolah

Sedangkan uji validitas variable turnover intention (Y) dapat dilihat pada Tabel 5 berikut ini:

Tabel 5

Hasil Uji Validitas Variabel Turnover Intention (Y)

\begin{tabular}{llll}
\hline No & Hitung & Tabel & Keterangan \\
\hline 1 & 0,486 & 0,254 & Valid \\
2 & 0,544 & 0,254 & Valid \\
3 & 0,478 & 0,254 & Valid \\
4 & 0,723 & 0,254 & Valid \\
5 & 0,723 & 0,254 & Valid \\
\hline \multicolumn{5}{c}{ Sumber: Data diolah }
\end{tabular}

b. Uji Reliabilitas

Hasil penelitian menunjukan bahwa semua variabel penelitian reliabel. Hal ini ditunjukkan pada Tabel 6 di bawah ini. 
Tabel 6

Hasil Uji Reliabilitas Variabel-variabel Penelitian

\begin{tabular}{ccl}
\hline Varibel Instrumen & $\begin{array}{c}\text { Cronbach's } \\
\text { Alpha }\end{array}$ & Keterangan \\
\hline Stress Kerja $\left(\mathrm{X}_{1}\right)$ & 0,606 & Reliabel \\
Kompensasi $\left(\mathrm{X}_{2}\right)$ & 0,582 & Reliabel \\
Tingkat Kepuasan Kerja $\left(\mathrm{X}_{3}\right)$ & 0,580 & Reliabel \\
Turnover Intention $(\mathrm{Y})$ & 0,580 & Reliable \\
\hline
\end{tabular}

Sumber: Data diolah

\section{Uji Asumsi Klasik}

Model regresi yang baik, harus memenuhi asumsi BLUE, yaitu Best LinearUnbiased Estimator.

a. Uji Normalitas

Uji normalitas digunakan untuk menguji apakah model regresi mempunyai distribusi normal ataukah tidak. Asumsi normalitas merupakan persyaratan yang sangat penting pada pengujian kebermaknaan (signifikansi) koefisien regresi. Model regresi yang baik adalah model regresi yang memiliki distribusi normal atau mendekati normal, sehingga layak dilakukan pengujian secara statistik.

Pengujian normalitas pada penelitian ini menggunakan metode KolmogorovSmirnov. Jika tingkat signifikansinya lebih besar dari 0.05, maka dapat dismpulkan data berdistribusi normal, sedangkan jika tingkat sigifikansinya lebih kecil dari 0.05 dapat dikatakan data tidak terdisribusi secara normal. Hasil uji normalitas penelitian dapat dilihat pada Tabel 7 di bawah ini.

Tabel 7

Hasil Uji Normalitas Kolmogorov-Smirnov Method

Unstandardized

Residual

\begin{tabular}{llr}
\hline \multirow{2}{*}{ Normal Parameters ${ }^{\mathrm{a}, \mathrm{b}}$} & & 61 \\
\hline \multirow{2}{*}{ Most Extreme Differences } & Mean & .0000000 \\
\cline { 2 - 3 } & Std. Deviation & .71414786 \\
\cline { 2 - 3 } & Absolute & .097 \\
\cline { 2 - 3 } & Positive & .084 \\
\cline { 2 - 3 } & Negative & -.097 \\
\hline Test Statistic & & .097 \\
\hline Asymp. Sig. (2-tailed) & & $.200^{\mathrm{c}, \mathrm{d}}$ \\
\hline
\end{tabular}
a. Test distribution is Normal.
b. Calculated from data.
c. Lilliefors Significance Correction.
d. This is a lower bound of the true significance.

Sumber: Data diolah

Berdasarkan hasil pengujian normalitas pada Tabel 7 di atas dapat disimpulkan bahwa keempat variabel penelitian ini berdistribusi normal.

b. Uji Multikolinearitas 
Uji multikolinearitas bertujuan untuk mengetahui apakah terdapat hubungan yang kuat antar variabel independen. Di dalam penelitian ini uji multikolinearitas menggunakan nilai VIF dan tolerance. Nilai tolerance untuk semua variabel independen lebih besar dari 0,1 dan nilai VIF kurang dari 10, maka dapat disimpulkan bahwa semua variabel independen bebas multikolinearitas.

c. Uji Heterokedastisitas

Heteroskedastisitas adalah varian residual dalam model tidak homogen. Uji untuk mendeteksi adanya gejala heteroskedastisitas dilakukan dengan dengan uji Gletser. Hasil uji heteroskedastisitas dapat dilihat pada Table 8 berikut.

Tabel 8

Hasil Uji Heteroskedastisitas

\begin{tabular}{ccc}
\hline Variabel & Sig. & Kesimpulan \\
\hline $\mathrm{X} 1=$ Stress Kerja & $0,105>0,05$ & Tidak terjadi \\
& & heteroskedastisitas \\
$\mathrm{X} 2=$ Kompensasi & $0,319>0,05$ & Tidak terjadi \\
& & heteroskedastisitas \\
X3 $=$ Tingkat & $0,342>0,05$ & Tidak terjadi \\
Kepuasan Kerja & & heteroskedastisitas \\
\hline
\end{tabular}

Dari Tabel 8 di atas terlihat bahwa nilai signifikansi untuk semua variabel independen terhadap dependen lebih besar dari 0,05, sehingga disimpulkan variabel penelitian bebas dari gejala heteroskedastisitas.

\section{Uji Individual dan Uji Simultan}

Pengujian selanjutnya adalah uji hipotesis. Uji Hipotesis pada penelitian ini dilakukan dalam 2 (dua) pengujian, yaitu:

a. Uji t dan Uji F

Uji t dilakukan untuk menentukan apakah variable-variabel independen secara parsial berhubungan terhadap variable dependennya. Adapun hasilnya terlihat pada table 9 berikut.

\begin{tabular}{cccc}
\multicolumn{4}{c}{ Tabel 9 } \\
Hasil Uji t \\
\hline Variabel & $\begin{array}{c}\text { Koefisien } \\
\text { Regresi (B) }\end{array}$ & $\begin{array}{c}\text { t } \\
\text { hitung }\end{array}$ & Sig \\
\hline Stress Kerja & 0.525 & 7.315 & 0,000 \\
Compensate & 0.594 & 8.467 & 0.000 \\
Kepuasan Kerja & 0.272 & 3.448 & 0,001 \\
Fhit = 61.235 & & & 0.000 \\
\hline
\end{tabular}

Sumber: Data diolah

Hasil penelitian menunjukan nilai t hitung pada variabel stress kerja sebesar 7.315 dengan nilai sig sebesar 0,000. Kriteria keputusan tolak Ho jika t hitung $>\mathrm{t}$ tabel atau sig < taraf kesalahan. Dari hasil penelitian dapat diketahui t hitung $=7.315$ yang artinya lebih besar dari t tabel $=2,0281$ atau sig $=0,000<$ taraf kesalahan $5 \%$ maka dapat disimpulkan bahwa stress kerja yang digunakan berpengaruh positif terhadap turnover 
intention. Hal ini ditunjukkan dari nilai koefisien regresi yang dihasilkan bertanda positif yaitu sebesar 0.525 .

Hasil uji t juga menunjukan bahwa nilai t hitung variabel kompensasi sebesar 8.467 dengan nilai sig sebesar 0,000. Kriteria keputusan tolak Ho jika t hitung > t tabel atau sig < taraf kesalahan, maka dari hasil penelitian dapat diketahui t hitung $=8.467$ yang lebih besar dari nilai t tabel sebesar 2,003. Maka dapat disimpulkan bahwa stress kerja berpengaruh positif terhadap turnover intention.

Hasil uji t penelitian juga menunjukan bahwa nilai t hitung variabel kepuasan kerja karyawan sebesar 3.448 dengan nilai sig sebesar 0,000. Kriteria keputusan tolak Ho jika $\mathrm{t}$ hitung > $\mathrm{t}$ tabel atau sig < taraf kesalahan, maka dari hasil penelitian dapat diketahui $\mathrm{t}$ hitung $=3.448$ yang lebih besar dari nilai $t$ tabel sebesar 2,003. Maka dapat disimpulkan bahwa stress kerja berpengaruh positif terhadap turnover intention.

Stress kerja, kompensasi, dan kepuasan kerja secara bersama-sama berpengaruh terhadap turnover intention. Hal ini dapat dilihat dari nilai $\mathrm{F}$ hitung sebesar 61.235 dengan nilai sig $=0,000$. Sedangkan nilai $\mathrm{F}$ table sebesar 2,77 pada tingkat kesalahan $5 \%$. Sehingga dapat disimpulkan bahwa terdapat pengaruh secara simultan antara stress kerja dan kompensasi terhadap turnover intention.

b. Koefisien Determinasi

Hasil penelitian menunjukan nilai $\mathrm{R}^{2}$ sebesar 0.591 , artinya bahwa variable stress kerja, variable kompensasi dan variable kepuasan kerja secara bersama-sama mampu menjelaskan variabel turnover intention sebesar $76,6 \%$ dan $23,4 \%$ adalah hal lain yang tidak menjadi bagian penelitian ini.

\section{Analisis dan Persamaan Regresi Linear Berganda}

Dari Tabel 9, didapat persamaan regresi linear berganda sebagai berikut:

$$
Y=-2,635+0,525 X_{1}+0,594 X_{2}+0,272 X_{3+} e
$$

Dimana:

$$
\begin{array}{ll}
\mathrm{X}_{1} & \text { : Stress Kerja } \\
\mathrm{X}_{2} & \text { : Kompensasi } \\
\mathrm{X}_{3} & \text { : Kepuasan Kerja Karyawan } \\
\mathrm{Y} & \text { : Turnover intention }
\end{array}
$$

Dapat dijelaskan sebagai berikut:

Model regresi $Y=-2,635+0,525 X_{1}+0,594 X_{2}+0,272 X_{3}+$ e menggambarkan bahwa variabel bebas (independen) Stres Kerja $\left(\mathrm{X}_{1}\right)$, Kompensasi $\left(\mathrm{X}_{2}\right)$, dan Tingkat Kepuasan Kerja $\left(\mathrm{X}_{3}\right)$ dalam model regresi tersebut dapat dinyatakan jika satu variabel independen berubah sebesar 1 (satu) dan lainnya konstan, maka perubahan variabel terikat (dependen) Turnover Intention Karyawan (Y) adalah sebesar nilai koefisien (b) dari nilai variabel independen tersebut. Konstanta (a) sebesar -2,635 memberikan pengertian bahwa jika Stress kerja $\left(\mathrm{X}_{1}\right)$, Kompensasi $\left(\mathrm{X}_{2}\right)$, dan Tingkat Kepuasan Kerja $\left(\mathrm{X}_{3}\right)$ secara serempak atau bersama-sama tidak mengalami perubahan atau sama dengan nol (0) maka besarnya Turnover Intention Karyawan (Y) sebesar -2,635 satuan. Hasil 
persamaan menunjukan bahwa variabel stress kerja, kompensasi dan tingkat kepuasan kerja memiliki koefisien positif. Hal ini berarti stres kerja, kompensasi dan tingkat kepuasan kerja dapat menaikan tingkat turnover intention karyawan di PT. Wahana Jaya Kirana.

Berdasarkan hasil pengujian regresi linear berganda menunjukkan bahwa stres kerja berpengaruh dan signifikansi terhadap turnover intention. Hasil uji regresi linear diperoleh nilai $t_{\text {hitung }}$ dengan tingkat signifikansi lebih kecil dari 0.05 artinya Ha1 diterima atau $\mathrm{H}_{0} 1$ ditolak. Hal ini berarti bahwa semakin tinggi tingkat stres kerja makan akan semakin tinggi tingkat turnover intention karyawan PT. Wahana Jaya Kirana. Dimana pada saat karyawan mengalami stres kerja berlebihan dapat mengakibatkan karyawan kehilangan kemampuan untuk mengambil keputusan dan perilakunya tidak teratur sehingga berimplikasi terhadap turnover intention.

Hasil Penelitian ini didukung oleh hasil penelitian (Nazenin \& Palupiningdyah, 2014) yang menyatakan bahwa stres kerja berpengaruh positif signifikan terhadap Turnover Intention. Hasil Penelitian (Yuda \& Ardana, 2017) juga menunjukkan bahwa stres kerja berpengaruh positif dan signifikan terhadap turnover intention.

Berdasarkan hasil pengujian regresi linear berganda menunjukkan bahwa kompensasi berpengaruh dan signifikansi terhadap turnover intention. Hasil uji regresi linear diperoleh nilai $t_{\text {hitung }}$ dengan tingkat signifikansi lebih kecil dari 0.05 artinya Ha2 diterima atau $\mathrm{H}_{0} 2$ ditolak. Hal ini dikarenakan perusahaan memberikan kompensasi ataupun bonus terhadap karyawanya yang memberikan kontribusi dan mengembangkan keterampilan kerjanya. Sehingga menurunkan minat karyawan untuk mencari pekerjaan lain dan keluar dari perusahaan.

Hasil Penelitian ini didukung oleh hasil penelitian (Khaidir et al., 2017) yang menyatakan bahwa kompensasi berpengaruh positif dan signifikan terhadap turnover intention karyawan .

Berdasarkan hasil pengujian regresi linear berganda menunjukkan bahwa tingkat kepuasan kerja berpengaruh dan signifikansi terhadap turnover intention. Hasil uji regresi linear diperoleh nilai $t_{\text {hitung }}$ dengan tingkat signifikansi lebih kecil dari 0.05 artinya $\mathrm{Ha} 3$ diterima atau $\mathrm{H}_{0} 3$ ditolak. Hal ini dikarenakan puas tidaknya karyawan tidak akan mempengaruhi niatnya untuk pindah ke perusahaan lain ataupun berhenti dari pekerjaanya. Semakin tinggi tingkat kepuasan kerja yang dirasakan oleh karyawan, maka akan semain tinggi pula komitmennya terhadap perusahaan. Walaupun karyawan tersebut menyukai dan puas dengan pekerjaanya, tidak menutup kemungkinan adanya indikasi turnover intention pada setap karyawan.

Hasil Penelitian ini didukung oleh hasil penelitian (Chairizal \& Djamil, 2019) yang menyatakan bahwa kepuasan kerja memiliki pengaruh yang signifikan secara langsung terhadap turnover intention. 


\section{Kesimpulan}

Berdasarkan hasil analisis dan pembahasan yang telah disusun dan yang telah diuji, kesimpulan dari penelitian bahwa hasil pengujian variabel Stres Kerja secara parsial berpengaruh terhadap Turnover Intention Karyawan di PT. Wahana Jaya Kirana. Hasil pengujian variabel Kompensasi secara parsial berpengaruh terhadap Turnover Intention Karyawan di PT. Wahana Jaya Kirana. Hasil pengujian variabel Tingkat Kepuasan Kerja secara parsial berpengaruh terhadap Turnover Intention Karyawan di PT. Wahana Jaya Kirana. Hasil pengujian menunjukan bahwa Stress Kerja, Kompensasi dan Kepuasan Kerja karyawan secara simultan berpengaruh terhadap variable turnover intention, hal tersebut dapat dilihat dalam uji $\mathrm{F}$, dimana nilai $\mathrm{F}_{\text {hitung }}=61,235$ lebih besar dari nilai $\mathrm{F}_{\text {tabel }} 2,77$. 


\section{DAFTAR PUSTAKA}

Arikunto, Suharsimi. (2016). Prosedur Penelitian Suatu Pendekatan Praktis. Jakarta: PT Rineka Cipta.

Asih, Gusti Yuli, Widhiastuti, H., \& Dewi, R. (2018). Stres kerja. Semarang: Semarang University Press.

Chairizal, Zulfahmi, \& Djamil, Masydzulhak. (2019). Pengaruh Kepemimpinan, kompensasi dan Lingkungan Kerja terhadap Kepuasan Kerja Karyawan Pt. xyz. Indikator, 3(3), 353562.

Dewi, Putu Sofia Andi, \& Sriathi, Anak Agung Ayu. (2019). Pengaruh Stres Kerja Terhadap Turnover Intention Yang Dimediasi Oleh Kepuasan Kerja. E-Jurnal Manajemen Universitas Udayana, 8(6), 3646.

Farchan, Fauzi. (2016). Teknikal Manajemen Sumber Daya Manusia Strategik Sebuah Paradigma Pengukuran Kinerja. Risâlah, Jurnal Pendidikan Dan Studi Islam, 3(1), 42-62.

Khaidir, Muhammad, Bachri, Ahmad Alim, \& Sugiati, Tinik. (2017). Pengaruh stres kerja, kompensasi dan kepuasan kerja terhadap turnover intention studi pada karyawan kontrak pt. Gagah satria manunggal Banjarmasin. JWM (Jurnal Wawasan Manajemen), 4(3), 175-186.

Kharismawati, Dewa Ayu Putu, \& Dewi, I. Gusti Ayu Manuati. (2016). Pengaruh Komitmen Organisasional, Dukungan Sosial, Dan Iklim Etika Terhadap Turnover Intention. Udayana University.

Lestari, Dian A. Y. U. (2015). Diskresi Dalam Pelaksanaan Program Keluarga Harapan (Pkh).

Meng, Xiangrui. (2013). Scalable simple random sampling and stratified sampling. International Conference on Machine Learning, 531-539. PMLR.

Nazenin, Syarifah, \& Palupiningdyah, Palupiningdyah. (2014). Peran Stres Kerja Dan Kepuasan Kerja Untuk Mengurangi Turnover Intention. JDM (Jurnal Dinamika Manajemen), 5(2).

Pangarso, Astadi, \& Ramadhyanti, Vidi. (2015). Pengaruh Lingkungan Kerja Non Fisik Terhadap Kepuasan Kerja Dosen Tetap Studi Pada Fakultas Komunikasi Dan Bisnis Universitas Telkom Bandung.

Sabilla, Ardhinia Padmarani, \& Sri Padmantyo, M. B. A. (2017). Pengaruh Stres Kerja Terhadap Turnover Intention Karyawan Dengan Dukungan Sosial Sebagai Variabel Moderating (Studi Empiris Pada PT. Driver Online Nusantara). Universitas Muhammadiyah Surakarta.

Sugiyono. (2017a). Metode Penelitian Kuantitatif, Kualitatif, dan R\&D. Bandung: Alfabeta.

Sugiyono. (2017b). Metode Penelitian Kuantitatif.

Susanto, Erwin, \& Agus Ulinuha, S. T. (2017). Pengujian Unjuk Kerja Dan Pengukuran Parameter Motor Induksi Satu Fasa. Universitas Muhammadiyah Surakarta.

Yuda, Ida Bagus Dwihana Parta, \& Ardana, I. Komang. (2017). Pengaruh Kepuasan Kerja dan Stres Kerja terhadap Turnover Intention pada Karyawan Hotel Holiday Inn Express" dalam E-Jurnal Manajemen Unud Volume 6 (hlm. 5319-5347). Bali: E-Jurnal Manajemen Unud. 